\title{
Study on Progressive Collapse Behavior of SRC Column-Steel Beam Hybrid Frame Based on Pushdown Analysis
}

\author{
Liusheng Chu, ${ }^{1}$ Gaoju Li, ${ }^{1}$ Danda Li, ${ }^{2}$ and Jun $\mathrm{Zhao}^{1}$ \\ ${ }^{1}$ Zhengzhou University, Henan Province, China \\ ${ }^{2}$ University of South Australia, Adelaide, SA, Australia \\ Correspondence should be addressed to Danda Li; danda.li@unisa.edu.au
}

Received 6 July 2017; Accepted 10 October 2017; Published 13 November 2017

Academic Editor: Songye Zhu

Copyright (c) 2017 Liusheng Chu et al. This is an open access article distributed under the Creative Commons Attribution License, which permits unrestricted use, distribution, and reproduction in any medium, provided the original work is properly cited.

\begin{abstract}
To investigate the progressive collapse behavior of Steel Reinforced Concrete (SRC) column-steel beam hybrid frame after the failure of key structural elements, a PQ-Fiber model for an 8-storey structure is established in ABAQUS program. Nonlinear dynamic and static pushdown analysis are carried out after the failure and removal of the bottom-middle and bottom-corner columns. Numerical results of both methods agree well with each other. Results show that SRC column-steel frame has good resistance to progressive collapse under dynamic instantaneous load. After sudden removal of a bottom middle column, the development of structural collapse exhibits two mechanisms, the beam mechanism and the catenary mechanism. When the structure is within small deformation range, the collapse resistance of the residual frame is provided by the beam bending moment capacity, which is beam mechanism. For large deformation situation, the collapse resistance is mainly provided by the beam tensile strength, which is catenary mechanism. However, with the removal of a bottom corner column, the residual structure only undergoes the beam mechanism even for large deformations. For future practical applications, the influence of the steel ratio, steel section size, and the vertical position of the removed key components are investigated through a detailed parametric study.
\end{abstract}

\section{Introduction}

After the progressive collapse of the Ronan Point apartment due to gas explosion in London in 1968 [1], the structure progressive collapse behavior has attracted great interests from designers and researchers. ASCE07-05 [2] defined the progressive collapse behavior as the spread of an initial local failure between members, eventually resulting in collapse of large part or even entire of the structure. Apart from the United States, Britain, and Europe, other countries and regions also introduced the corresponding structure progressive collapse design specifications [2-7].

Many experimental and theoretical studies on the progressive collapse behavior of reinforced concrete frame and steel frame have been reported, including structural collapse mode and dynamic increasing factor. Tsai and Lin [8] conducted nonlinear static and nonlinear dynamic analyses on the progressive collapse behavior of the reinforced concrete building subjected to column failure. By using alternate path methods, J. Kim and T. Kim [9] studied the progressive collapse-resisting capacity of steel frame. The results showed that the progressive collapse risk was highest when a corner column was suddenly removed. For practical applications, Liu [10] proposed an empirical formula through calculating the dynamic increasing factor (DIF), which can be used with nonlinear static analysis to assess the potential of progressive collapse for steel frames. Masoero et al. [11] presented an analytical model for the collapse of a 2D frame after column removal, which could be used to estimate the loads of collapse initiation. Based on DOD2010 [3] design process Liang et al. [12] investigated the progressive collapse behavior of a threestorey steel frame structure which was designed according to Chinese Design Code. Yi et al. [13] conducted a quasi-static test method to analyze the progressive collapse process of a RC frame structure after the failure of one of the bottom columns. Li et al. [14] conducted a nonlinear static pushdown analysis on the progressive collapse bearing capacity of the whole cast-in-place reinforced concrete frame loaded under different seismic intensities. The results showed that the seismic design improved the progressive collapse capacity of 


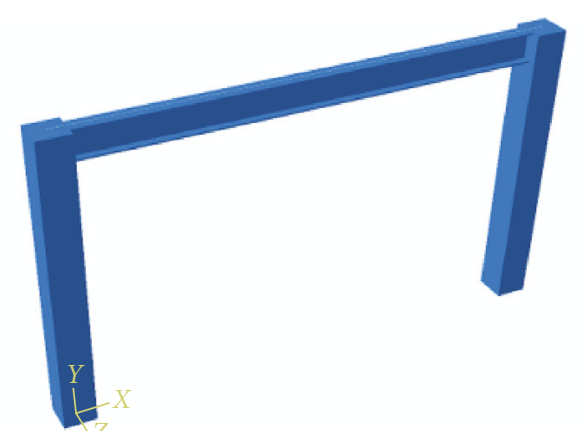

FIGURE 1: Finite element model of a hybrid frame.

the frame structure under the beam mechanism but has a limited increase when the structure is under the catenary mechanism. Fascetti et al. [15] proposed a new procedure from nonlinear static and dynamic analyses to evaluate the robustness of RC frame to progressive collapse after a sudden loss of vertical load carrying.

From the above literature, it can be seen that the current theory or experiment studies on progressive collapse are mostly about reinforced concrete structures (RC) and steel structures. In practical engineering, other than just steel structure or RC structures, more and more hybrid structures are developed to meet higher requirement of structure durability, performance, and economic and other aspects. A type of hybrid frame which consists of Steel Reinforced Concrete (SRC) column and structural steel beam is one of the widely used hybrid structures. It was proved to have good seismic performance and economic advantages compared with just structure steel frame or RC frame structure. However, there is little research on the progressive collapse ability of this SRC column-steel beam hybrid frame structure. It is most likely to occur under occasional impact loads such as explosion.

This paper addresses the progressive collapse behavior of SRC column-steel beam hybrid frame. An 8-storey hybrid frame structure was designed according to the current Seismic Code of China, and the pushdown analysis was carried out by using alternate path method under the occasional load. Based on the analysis results, the progressive collapse ability and collapse mechanism of the hybrid frame were studied, and the influence of the parameters such as the steel ratio of SRC column, steel section size, and the vertical position of removing key components were also investigated.

\section{Calculation Method and Verification}

2.1. FEM Modeling of Steel Reinforced Concrete (SRC) ColumnSteel Beam Hybrid Frame Structure. In this study, ABAQUS program was employed for structure analysis. The hybrid frame components are all modeled by the two-dimensional plane element. This type of unit allows shear deformation, and takes into account the limited axial strain. The finite element model of a hybrid frame is shown in Figure 1. The reinforcing bars are defined by the $*$ rebar keyword, and the number, position, and size of the each rebar are modeled

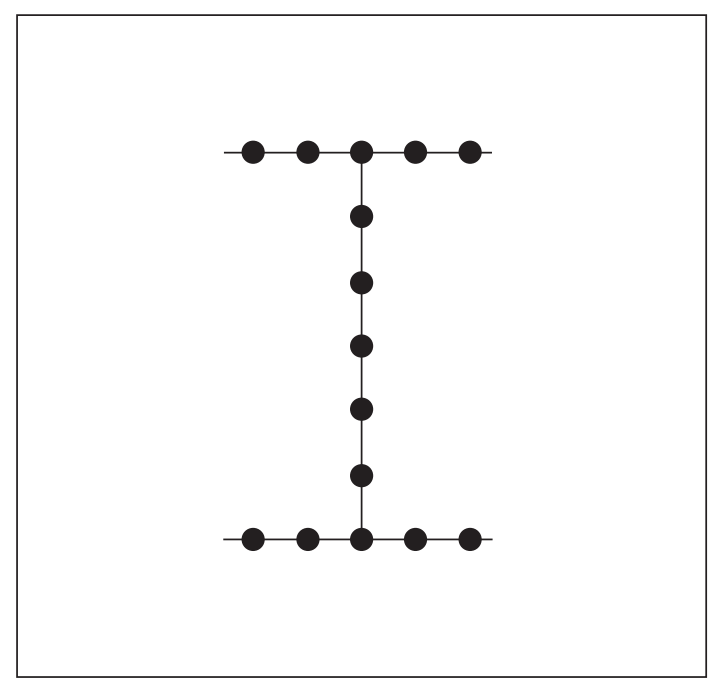

FIGURE 2: Discretization of the steel in the SRC column.

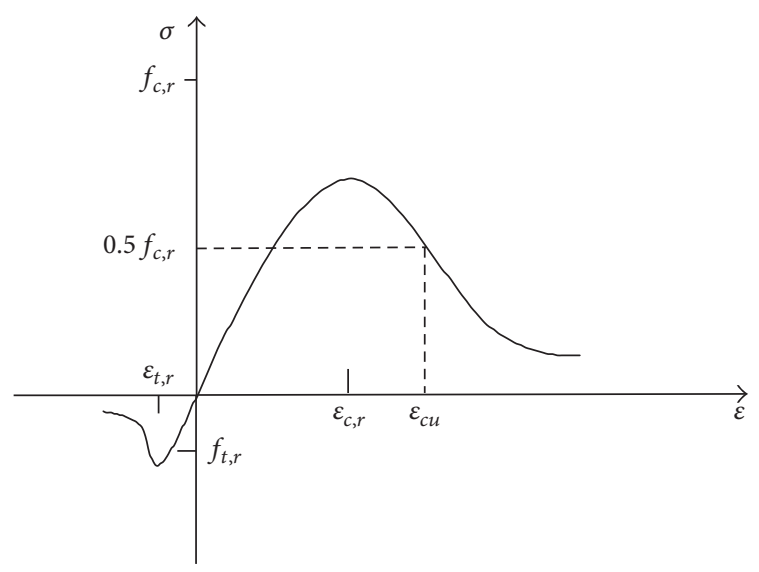

FIGURE 3: Stress-strain curve of concrete.

according to the actual situation. The steel in the SRC column will be separated into several steel fibers, as shown in Figure 2.

The concrete 03 in PQ-Fiber was used for the concrete constitutive model. This model is based on the concrete skeleton curve in current Chinese Code [16], in which the tensile strength of the concrete model can be considered. The stress-strain curve (Figure 3) of concrete under uniaxial tension can be determined by (1a), (1b), (1c), and (1d).

$$
\begin{aligned}
\sigma & =\left(1-d_{t}\right) E_{c} \varepsilon \\
d_{t} & = \begin{cases}1-\rho_{t}\left[1.2-0.2 x^{5}\right] & x \leq 1 \\
1-\frac{\rho_{t}}{\alpha_{t}(x-1)^{1.7}+x} & x>1,\end{cases} \\
x & =\frac{\varepsilon}{\varepsilon_{t, r}} \\
\rho_{t} & =\frac{f_{t, r}}{E_{c} \varepsilon_{t, r}}
\end{aligned}
$$


where $d_{t}$ is tensile damage evolution parameters of concrete, $\alpha_{t}$ is decreasing parameters of concrete tensile constitutive curve, $f_{t, r}$ is uniaxial tensile strength of concrete, $\varepsilon_{t, r}$ is the concrete strain corresponding with $f_{t, r}$, and the parameter values in the formula are taken as in Chinese Code.

The stress-strain curves of concrete under uniaxial compression (Figure 3) can be determined by (2a), (2b), (2c), (2d), and $(2 \mathrm{e})$ :

$$
\begin{aligned}
\sigma & =\left(1-d_{c}\right) E_{c} \varepsilon, \\
d_{c} & = \begin{cases}1-\frac{\rho_{c} n}{n-1+x^{n}} & x \leq 1 \\
1-\frac{\rho_{c}}{\alpha_{c}(x-1)^{2}+x} & x>1,\end{cases} \\
\rho_{c} & =\frac{f_{c, r}}{E_{c} \varepsilon_{c, r}}, \\
n & =\frac{E_{c} \varepsilon_{c, r}}{E_{c} \varepsilon_{c, r}-f_{c, r}}, \\
x & =\frac{\varepsilon}{\varepsilon_{c, r}},
\end{aligned}
$$

where $d_{c}$ is the compressive damage evolution parameter, $\alpha_{c}$ is decreasing parameters, $f_{c, r}$ is uniaxial compressive strength of concrete, and $\varepsilon_{c, r}$ is the concrete strain at peak stress. The parameter values in the formula are taken as in Chinese Code [16].

USTEEL02 model of PQ-FIBER is used for the constitutive model of steel and rebar. Figure 3 shows the uniaxial stress-strain curve, where $k$ is the hardening stiffness coefficient which represents the ratio of the second stage stiffness and the elastic modulus of the steel and is taken as 0.01 in this model.

In order to verify the applicability of the modeling in ABAQUS program of the SRC column-steel beam hybrid frame, the seismic behavior of the hybrid frame experiment conducted by Li and Zhao [17] was simulated. A one-way horizontal load is applied to the planar frame in the finite element model in Figure 1, with the analysis results shown in Figure 5. It indicated that the rigidity of the analysis curve is consistent with the stiffness of the test curve in the elastic stage. Beyond elastic stage the analyzed stiffness is slightly larger than the test value. The main reason is that the load on the structure in experimental test is cyclic load, while in the analysis it is monotonically horizontal load. Another possible reason is that the slip between the steel section and the concrete is not considered in the simulation, hence resulting in a faster drop in stiffness value than the tested value. However, it can be concluded that the two curves fit well.

The good agreement between the FEM method and the experimental results shows that it is feasible to carry out the elastoplastic simulation analysis to the SRC column-steel beam hybrid frame in the ABAQUS with PQ-FIBER.

2.2. Direct Dynamic Analysis. The straightforward progressive collapse capacity analysis of a frame is dynamic analysis on the remaining structure under the instantaneous load from the force redistribution due to sudden collapse or failure of one column (Khandelwal and El-Tawil, 2011 [18]). However, the direct dynamic analysis method is time consuming and the massive data obtained during the analysis is not easy to interpret into design procedure. In this paper, a simplified pseudostatic analysis method is proposed to analyze the remaining structural system through applying a downward static load at the column collapsing point to represent the unbalanced reaction force from the column. This method is also named pushdown method. The direct dynamic analysis method here will be used as verification for the presented pushdown method.

2.3. Pushdown Method (Nonlinear Static Analysis). For the model considered in this paper, the material nonlinearity of steel and concrete needs to be considered in the analysis due to the large deformation estimated. In addition, due to the large number of elements involved in this model, the displacement-controlled nonlinear static method will be employed to improve the efficiency and accuracy of analysis. The structure dynamic effect will be considered and the dynamic increasing factor will be investigated.

In accordance with DOD2010 [3] and GSA2003 [4], after some structural components are removed and the initial destruction occurs, the residual structure damage is allowed. However, this damage should be restricted to avoid the progressive collapse damage in the residual structure. There is also a need to analyze the capacity of the remaining structure, and its progressive collapse ability.

According to US specification GSA2003 [4], if using the alternate load path method for progressive analysis, some of the specific vertical load-bearing components of structure need to be removed, and the overall structure damage should be controlled within the specified allowable range. In this paper, nonlinear static pushdown analysis of SRC columnsteel beam hybrid frame is carried out using this method, removing SRC columns here in our case. In the pushdown analysis process, load is gradually applied to the structure and increased until the damage occurs. Then the relationship between structural resistance and deformation is able to be obtained, which will be used to determine the progressive ability of the structure.

Specifically in the ABAQUS program, the failure component is firstly removed by using life and death unit method, which can be achieved by the command of * MODELCHANGE, TYPE = ELEMENT, REMOVE. Then the linear load will be gradually applied to the beam until the final destruction of the structure.

As a verification pushdown method is used to simulate a $1 / 3$ reinforced concrete frame experiment, which is designed according to the reinforced concrete design specification [13]. The gradual failure of the column in the bottom of the frame (Figure 6) is simulated by decreasing the load which was applied by jack. Based on concrete material model (the PQ-Fiber unit, in Figure 3) and steel constitutive model (Figure 4), the above-mentioned experimental progressive process was simulated by ABAQUS program. The middle column unloading force-unloading displacement curves of experimental and simulation are shown in Figure 6. It can be 


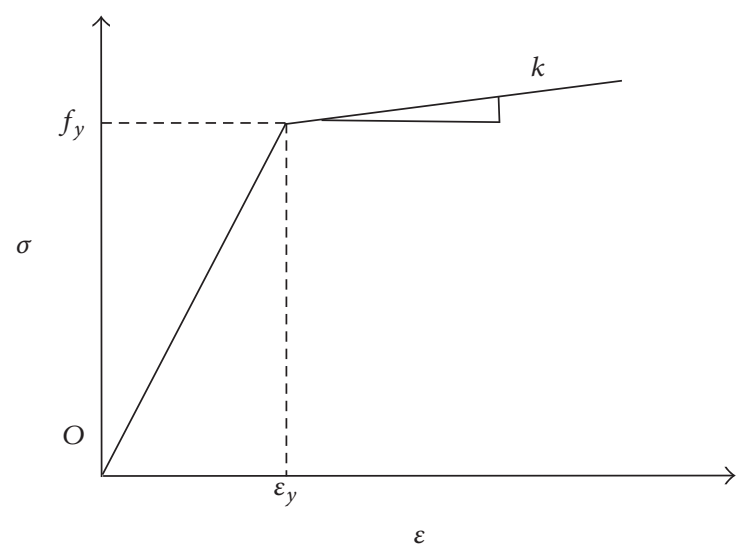

FIGURE 4: Stress-strain curve of steel.

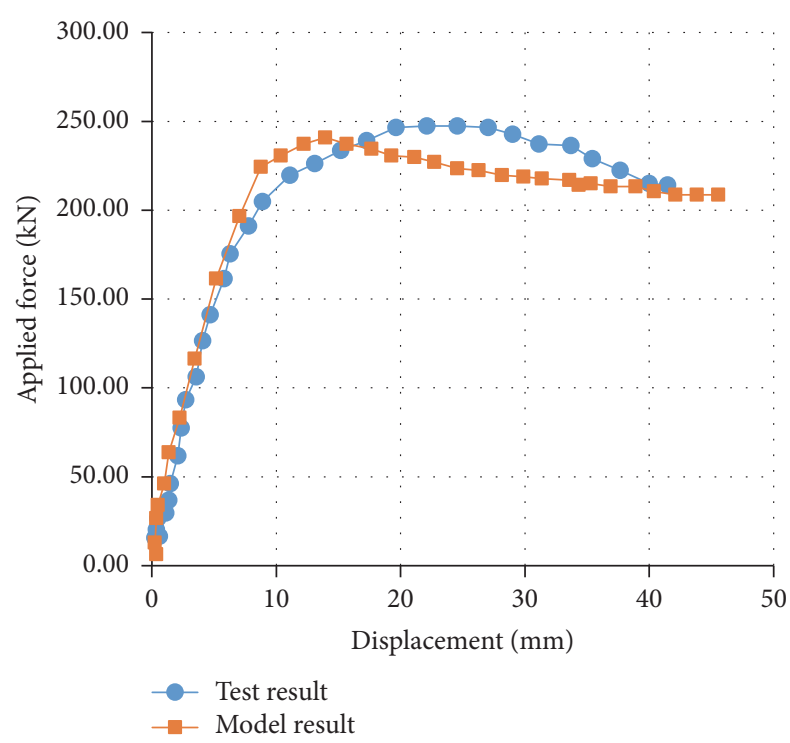

FIGURE 5: Load-displacement curve of SRC hybrid frame.

seen from the figure that the simulation results of both the elastic section and the plastic section are in good agreement with the experimental results, which shows that the progressive collapse of the structure can be effectively simulated, and the PQ-FIBER model can be used to simulate the progressive collapse behavior of concrete.

Assuming the relationship between applied load $F_{F L}$ and the vertical deflection $y$ at the collapse column point obtained from above static analysis is

$$
F_{F L}=f(y) .
$$

The maximum dynamic displacement $y_{d}$ after considering the impact effect due to sudden collapse of the column can be obtained through solving the following equation:

$$
F_{F L} \bar{y}_{d}=\int_{0}^{\bar{y}_{d}} f(y) d y
$$

where the $F_{F L} \bar{y}_{d}$ on the left side of the equation means the work down by the applied load $F_{F L}$, and the integral term
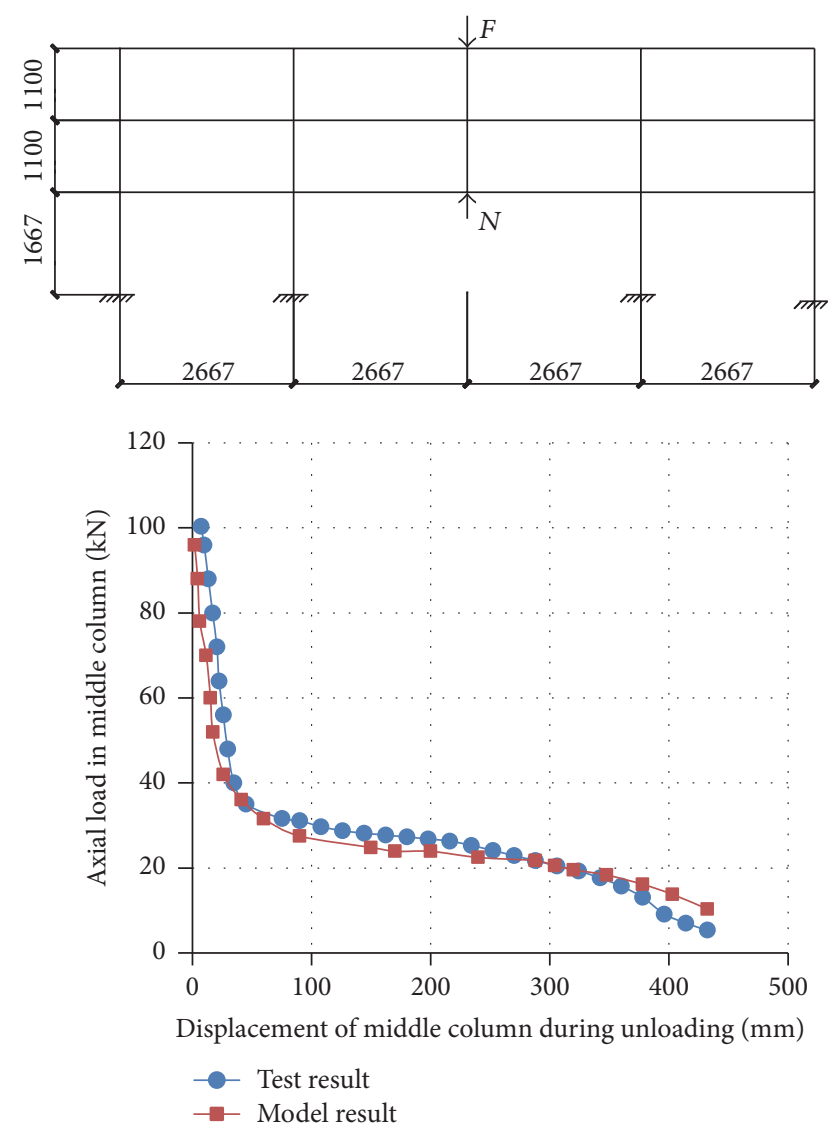

Figure 6: Load-displacement curves of pushdown analysis and test results.

$\int_{0}^{\bar{y}_{d}} f(y) d y$ on the right side means the deformational energy stored in the structure. Considering the damping effect, the maximum dynamic displacement $y_{d}$ can be expressed as

$$
y_{d}=\frac{\left[1+e^{-\xi \pi}\right] \bar{y}_{d}}{2}
$$

where $\xi$ is the damping ratio for the system, $\xi=0.02$ for steel structures, and $\xi=0.05$ for concrete structures. For the hybrid structure in this paper, 0.02 is used for damping ratio for conservative analysis.

In order to make the analysis result more clear, this paper adopts the concept of the load resistance coefficient proposed by Khandelwal and El-Tawil [18], which was defined as the ratio of the vertical incremental load on the beam to the normal load on it, as shown in the following formula:

$$
F_{\mathrm{OL}}=\frac{F_{F L}}{F_{\mathrm{O}}},
$$

where $F_{O L}$ is the load resistance coefficient, $F_{O}$ is initial axial force in the collapsed column, and $F_{F L}$ is the vertical incremental load on the beam.

Considering (6), (4) can be normalized as

$$
F_{\mathrm{OL}} \bar{y}_{d}=\int_{0}^{\bar{y}_{d}} f_{\mathrm{OL}}(y) d y
$$




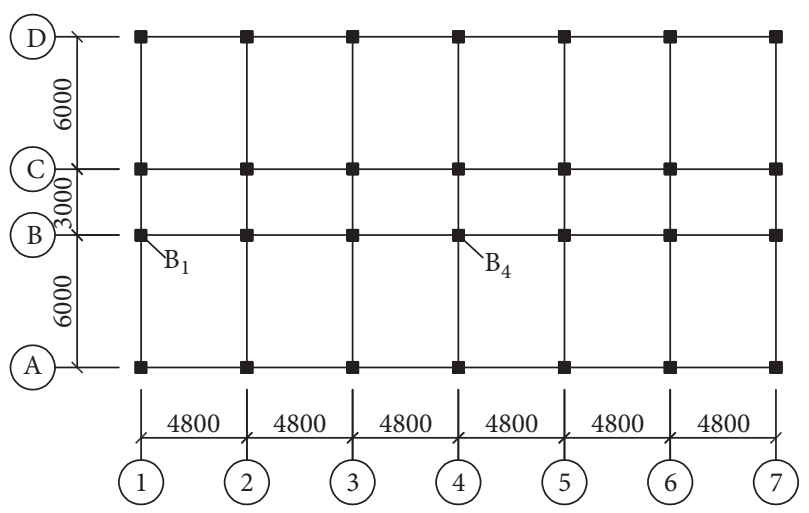

FIGURE 7: The planar arrangement of the hybrid frame structure.

where $f_{\mathrm{OL}}$ is the static relationship function between load resistance coefficient and vertical displacement at the collapse column point.

According to DOD2010 [3], the subsequent destruction of structural residual components should be strictly limited, which means that the residual structural components cannot exceed the ultimate plastic deformation of the component. In this paper, the progressive collapse failure criterion of the structure follows DOD2010 [3] requirement and the displacement difference at both ends of the steel beam is limited to $1 / 10$ of span.

As for the removal of key components in progressive collapse analysis, GSA2003 [4] suggested four types of typical bottom frame columns, including internal columns, midcolumn in long side, mid-column in short side, and corner columns. DOD2010 [3] also requires removal of the side column of the upper structure. This is because the bottom columns are more likely to have accidental loads, while the upper side columns are more likely to be exposed to gas explosion and the impact of flying objects. According to Chinese progressive collapse specification, bottom columns and upper floor columns where the cross sections change are the key components to be removed.

In this paper, pushdown analysis will be carried out by removing the bottom corner column and the middle column. Their effect on structure progressive collapse behavior was analyzed and parameters analysis was investigated.

\section{Main Parameters and Calculation Principles}

3.1. Design Parameters. The calculation model is 8-storey SRC column-steel beam hybrid frame structure. The plan drawing is shown in Figure 7. The storey height is 3.6 meters. There are 6 continuous spans along $X$ direction and 3 span along $Y$ direction. Column cross sections in storeys 1-4 are $550 \mathrm{~mm} \times 550 \mathrm{~mm}$ and in storeys $5-8$ are $500 \mathrm{~mm} \times 500 \mathrm{~mm}$. Concrete compressive strength is $40 \mathrm{MPa}$, and steel yield strength is $235 \mathrm{MPa}$.

3.2. Load and Member Details. Dead loads on both floor and roof are $5.0 \mathrm{kN} / \mathrm{m}^{2}$, live loads on floor and roof are $2.0 \mathrm{kN} / \mathrm{m}^{2}$ and $0.5 \mathrm{kN} / \mathrm{m}^{2}$, respectively. The combination of load effects
TABLE 1: Cross section of SRC column.

\begin{tabular}{lccc}
\hline $\begin{array}{l}\text { SRC } \\
\text { column }\end{array}$ & $\begin{array}{c}\text { Section size } \\
(\mathrm{mm})\end{array}$ & $\begin{array}{c}\text { Steel size }(\mathrm{mm}) \\
(\text { height } \times \text { width } \times \\
\text { web } \times \text { flange })\end{array}$ & $\begin{array}{c}\text { Longitudinal } \\
\text { reinforcement }\end{array}$ \\
\hline $\begin{array}{l}\text { 1-4 } \\
\text { storey }\end{array}$ & $550 \times 550$ & $300 \times 300 \times 12 \times 16$ & $12 \Phi 18$ \\
$\begin{array}{l}5-8 \\
\text { storey }\end{array}$ & $500 \times 500$ & $240 \times 240 \times 10 \times 17$ & $12 \Phi 16$ \\
\hline
\end{tabular}

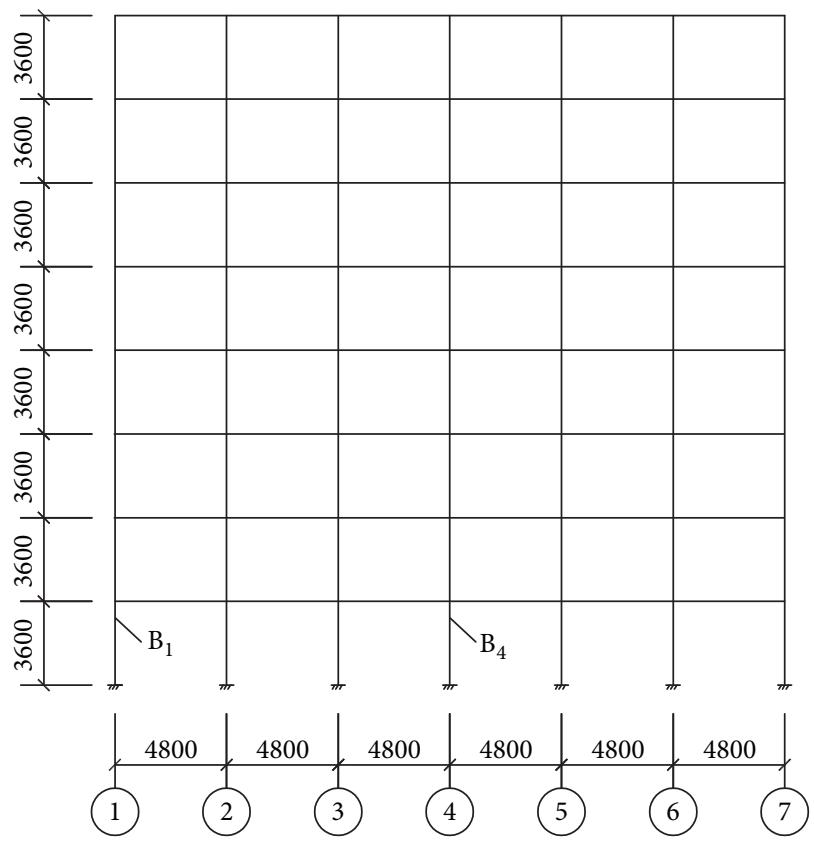

Figure 8: Elevation drawing of the hybrid frame structure.

in this paper is calculated according to the Code for AntiCollapse Design of Building Structures [19] issued by the China Engineering Construction Association in 2014. The detail of the SRC column is listed in Table 1.

3.3. Analysis of Progressive Collapse Behavior. As shown in Figure 8 , for the structure being considered, the bottom middle column B4 was removed and the structure was subjected to pushdown analysis. The second analysis is where the bottom corner column $\mathrm{B} 1$ was removed.

3.4. Progressive Collapse Behavior after Removal of Bottom Middle Column B4. The middle column B4 is removed from the frame and the column top is used as control node. Both dynamic analysis and pseudostatic pushdown analysis were carried out using ABAQUS program.

3.4.1. Dynamic Analysis Results. The dynamic displacement of the middle column upper node and the bending moment of the connecting beam are shown in Figures 9 and 10. It can be seen that the maximum dynamic response (at the beginning of the loading) is nearly double the value of the stable static response, which is similar to previous studies $[10,12,14]$. It 


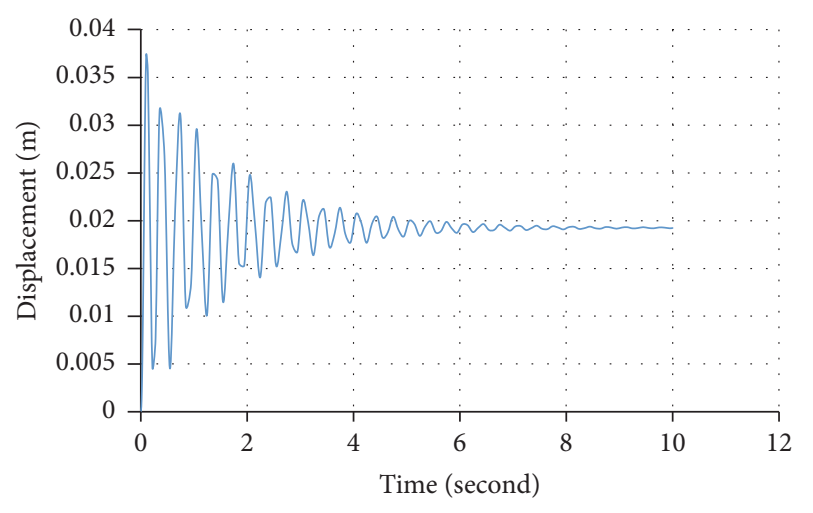

FIGURE 9: The displacement of middle column upper node versus time in dynamic model.

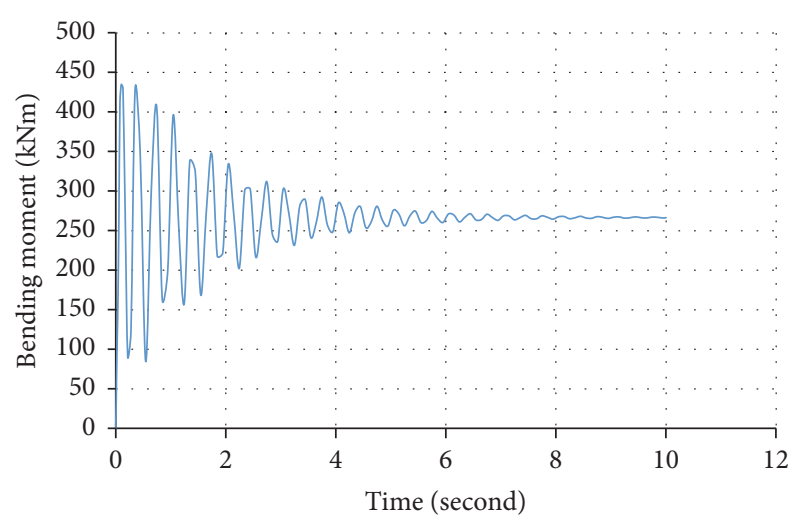

FIgURE 10: The bending moment of connecting beam to middle column upper node versus time in dynamic model.

indicates that the impact increasing effect cannot be ignored for structures with sudden column failure or collapse.

3.4.2. Pushdown Analysis Method. The deformation of frame after collapse of column B4 is shown in Figure 11. Figure 12(a) shows the relationship between the vertical displacement and the resistance coefficient of the column top node after the failure of the bottom middle column B1 from static analysis. Based on (5) and (7) and Figure 12(a), the dynamic displacement-resistance coefficient curve can be obtained as shown in Figure 12(b). It can be seen from the figure that the residual structure after removal of the column has a strong vertical stiffness and remaining capacity. The dynamic vertical displacement of the node is around $0.037 \mathrm{~m}$, which is exactly the same as shown in the dynamic analysis results of Figure 8. Considering Figure 12(a), the pseudostatic load coefficient is 1.94 . If the dynamic displacement reaches the standard limit of $0.48 \mathrm{~m}$, which is equivalent to $1 / 10$ of beam span, the load resistance coefficient is 2.62. It is obvious that the structure does not collapse after the removal of the column B1 from this SRC column-steel beam hybrid frame.

Figure 13 shows the bending moment-resistance coefficient curve of the steel beam which is connected with the removed column B4 after static analysis. It can be seen that the bending moment of the steel beam increases abruptly with the increase of the resistance coefficient at the beginning of loading, with compressive axial force which increases linearly at a slow rate. The residual structure mainly depends on the bending capacity of the beam, and this stage is the beam mechanism stage. When the resistance coefficient is increased to 1.8 at the bending moment of $429.5 \mathrm{kNm}$ the beam reaches its ultimate plastic moment. After that point, the bending moment gradually becomes more stable. Considering the fact that the pseudostatic load coefficient is 1.94 after removal of the column, the maximum dynamic ending moment within the steel beam can be considered as $430 \mathrm{MPa}$, which is exactly the same as the dynamic analysis result in Figure 10.

Figure 14 shows the axial force-resistance coefficient curve of the steel beam which is connected with the removed column B1. These figures show that, after resistance coefficient of 1.8, the slope of the curve becomes larger and the axial force in the beam increases rapidly. The hybrid frame enters the catenary phase gradually through the transition phase, and its anticollapse ability mainly depends on the axial tensile bearing capacity of the steel beam.

\subsection{Progressive Collapse Behavior after Removal of Bottom} Corner Column. The corner column B1 is removed from the frame and the column top is used as control node. Both dynamic analysis and pseudostatic pushdown analysis were carried out using ABAQUS program. From the pseudostatic pushdown analysis the deformation of overall structure is analyzed and shown in Figure 15.

Figure 16(a) shows the static analysis results for resistance coefficient-displacement curve of the frame after the bottom corner column is removed. Similar to the bottom middle column failure, the dynamic displacement-resistance coefficient curve for the corner column collapse mode can be obtained based on Figure 16(a) and (5) and (7) as shown in Figure 16(b). It can be seen from the figure that the residual structure after removal of the column has a strong vertical stiffness and remaining capacity. The dynamic vertical displacement of the node is around $0.065 \mathrm{~m}$. Considering Figure 16(a), the pseudostatic load coefficient is 1.51 at the displacement of $0.065 \mathrm{~m}$. If the dynamic displacement reaches the standard limit of $0.48 \mathrm{~m}$, which is equivalent to $1 / 10$ of beam span, the load resistance coefficient is 1.79 (Figure 16(b)). It is obvious that the structure does not collapse after the removal of the corner column from this SRC column-steel beam hybrid frame.

The relationships of the beam bending moment versus resistance coefficient of the structure after bottom corner column removed are given in Figure 17. It can be seen from Figure 17 that the moment of the beam at the beginning of the loading increases sharply, which shows a very obvious "beam mechanism." Then, when the resistance coefficient increased to 1.01 , the plastic hinge began to develop in the beam ends section with the bending moment changing more slowly. After this point the residual structure has been unable to continue to withstand more loads. Because the pseudostatic load coefficient is 1.51 , the beam already comes into plasticity during the impact procedure due to sudden collapse of corner column. 


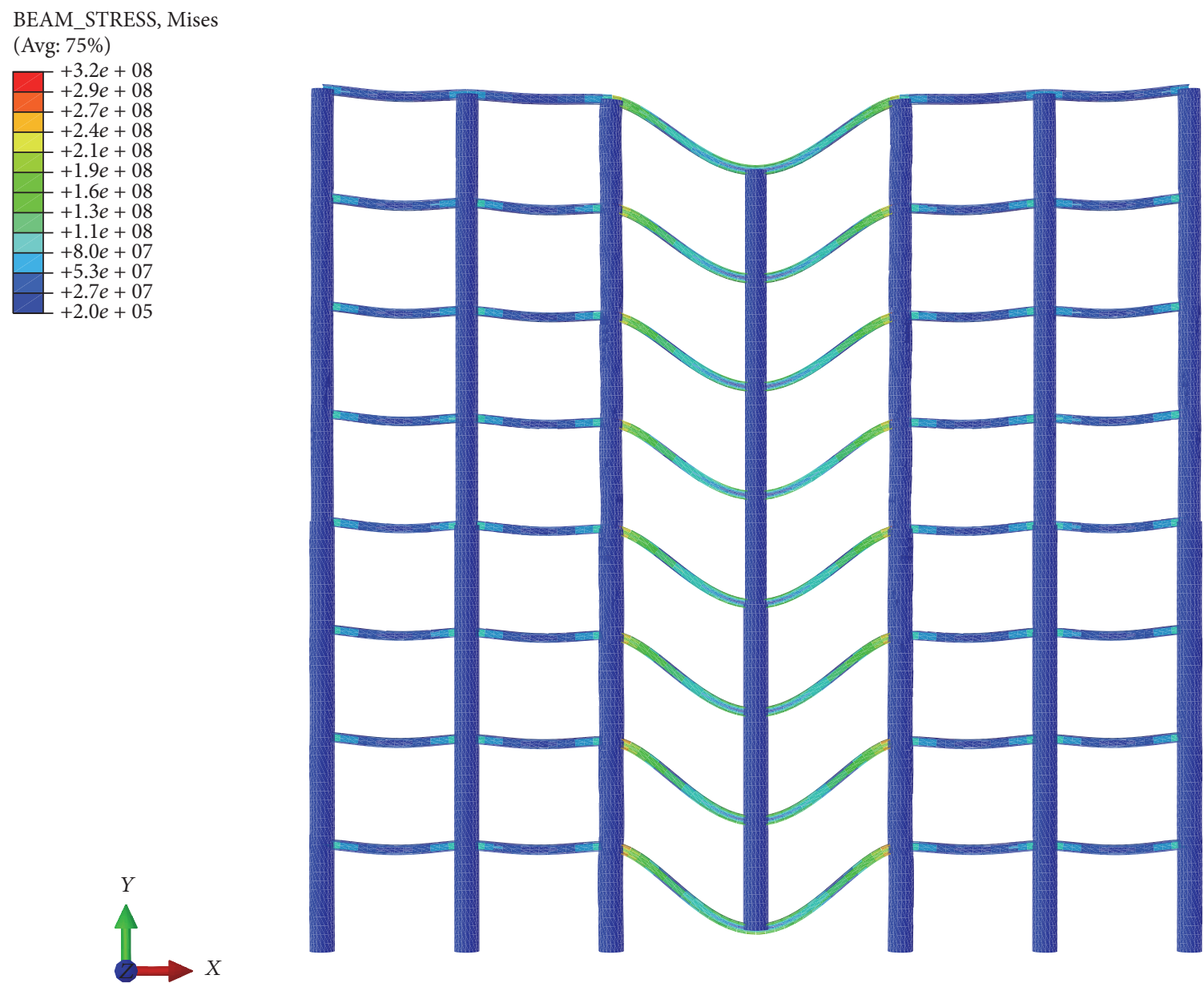

FIGURE 11: Deformation cloud diagram of the hybrid frame after the failure of the bottom middle column.

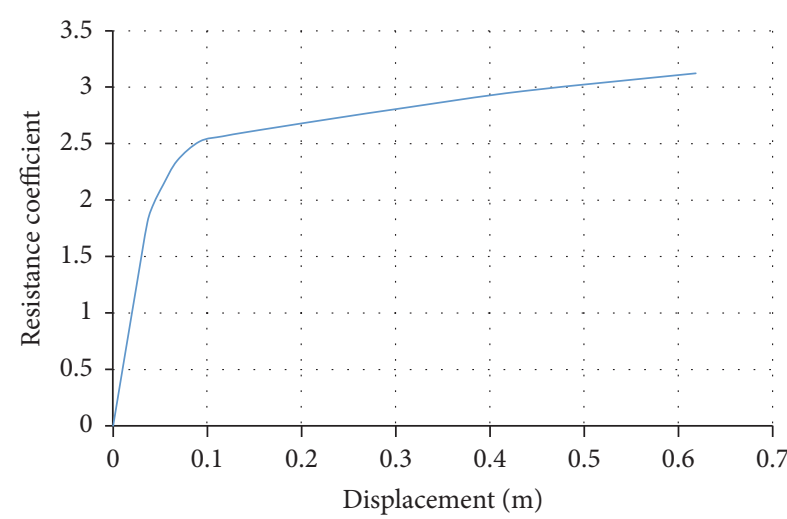

(a) Static displacement-resistance coefficient curve

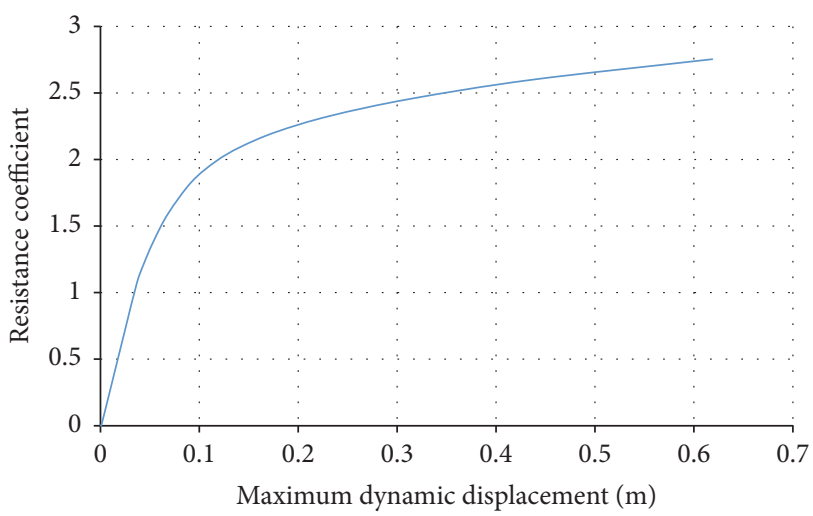

(b) Dynamic displacement-resistance coefficient curve

FIGURE 12: Vertical displacement-resistance coefficient curve of the hybrid structure after the failure of the bottom middle column.

The relationship of the axial force versus resistance coefficient of the structure after bottom corner column is removed is given in Figure 18. It can be seen that the beam is always in compression during the loading process, while in the bottom middle column removal case the beam is mainly in axial tensile strengh (Figure 14). In summary, after the removal of the bottom corner column, the upper residual structure (the part related to the removed column) becomes a geometrically variable system. When the bending moment of the beam reaches the ultimate moment, the residual structure cannot bear any more vertical load, and there is no "catenary mechanism" system formed after the "beam mechanism" stage. 
TABLE 2: Different SRC column-steel ratio parameters for models (1)-(3).

\begin{tabular}{|c|c|c|c|c|}
\hline Model & $\begin{array}{c}\text { Steel size in } 1-4 \text { storeys } \\
(\mathrm{mm})(\text { height } \times \text { width } \times \\
\text { web } \times \text { flange })\end{array}$ & $\begin{array}{l}\text { Steel size in } 5-8 \text { storeys } \\
(\mathrm{mm})(\text { height } \times \text { width } \times \\
\text { web } \times \text { flange })\end{array}$ & $\begin{array}{c}\text { Steel ratio in } 1-4 \\
\text { storeys (\%) }\end{array}$ & $\begin{array}{c}\text { Steel ratio in 5-8 } \\
\text { storeys (\%) }\end{array}$ \\
\hline (1) & $300 * 300 * 8 * 12$ & $240 * 240 * 8 * 12$ & 3.2 & 3.1 \\
\hline (2) & $300 * 300 * 12 * 16$ & $240 * 240 * 10 * 17$ & 4.7 & 4.8 \\
\hline (3) & $300 * 300 * 16 * 28$ & $240 * 240 * 18 * 24$ & 7.4 & 6.9 \\
\hline
\end{tabular}

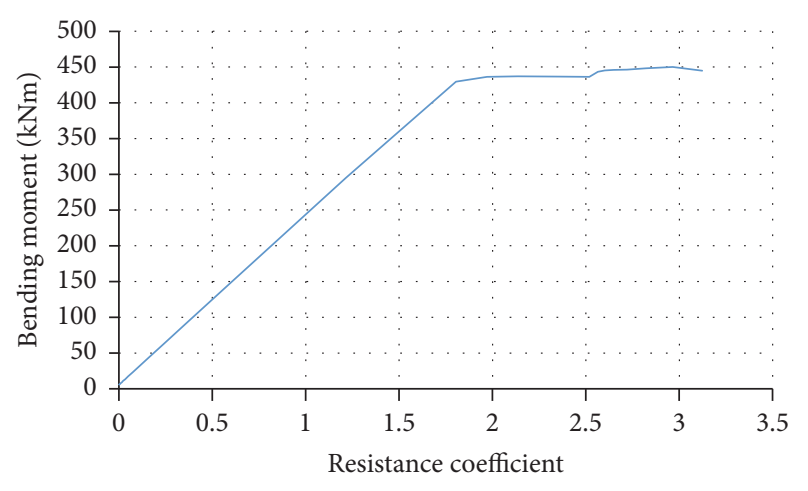

FIGURE 13: Bending moment-resistance coefficient curve of the steel beam connected with the removed middle column.

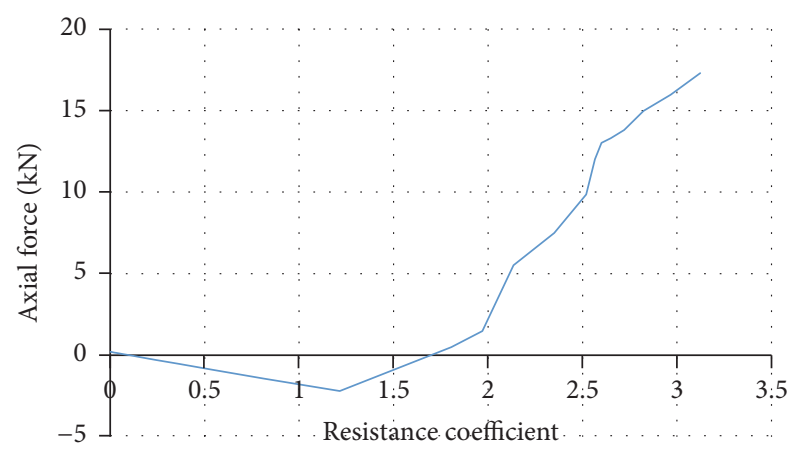

FIGURE 14: Axial force-resistance coefficient curve of the steel beam connected with the removed middle column.

From the above discussion, it can be seen that there are two stages in the progressive collapse process of SRC columnsteel beam hybrid frame: "beam mechanism" and "catenary mechanism," which is similar to the failure process of RC frame and steel frame $[8,9,11-15]$. As the catenary mechanism mainly depends on the tensile force of the steel beam, it is important to improve the tensile capacity of the beam section to improve the progressive collapse ability of the structure. At the same time, since the catenary mechanism can not be formed in the hybrid frame after the removal of the corner columns, its progressive collapse ability is weak. So the bottom corner column should be strengthened in the progressive collapse design.

\section{Parametric Analysis of Progressive Collapse Behavior of SRC Column-Steel Beam Hybrid Frame}

4.1. Effect of Steel Ratio of SRC Column. SRC column is the basic vertical load-bearing component in a hybrid frame. According to the design rules of steel composite structure [20]: the minimum steel ratio of SRC components is $3 \%$, the appropriate steel ratio can be $5 \%$ to $8 \%$, and thickness of steel component should be not less than $6 \mathrm{~mm}$. Based on the above requirements, the steel ratio in this paper is increased by increasing the thickness of the flange plate and the thickness of the web without changing the flange width and section height. Table 2 shows the three different SRC column-steel ratio parameters for the model.

The SRC column-steel beam hybrid frame analysis model was established according to the three different column-steel ratio parameters in Table 2; then the SRC column of the same position was removed and the pushdown analysis was carried out, respectively.

4.1.1. Removing Bottom Middle Column. Figure 18 shows the displacement-resistance curve of the three hybrid frame models with different steel ratio after the bottom middle column was removed.

It can be seen from Figure 19 that when the limit of damage criterion is reached (i.e., the vertical displacement of 0.48 points), the resistance coefficients of the three models are $2.73,3.02$, and 3.36 , respectively. This shows that the progressive collapse behavior of the system increases with the increase of steel ratio. This is because the vertical load is the main control load after the removal of vertical components. Increasing the steel ratio of SRC column can improve the overall stiffness of the structure and hence slightly improve the anticollapse bearing capacity of the structure.

4.1.2. Removing Bottom Corner Column. Figure 20 shows the displacement-resistance curve of the three models with different steel ratio after the bottom corner column was removed.

As can be seen from the figure, with the increase of steel ratio in the SRC columns, the resistance coefficient growth rate is very small. This is a similar conclusion as the removal of middle column. Increasing the steel ratio of the SRC column has a slight effect on the anticollapse ability of hybrid frame structure.

4.2. Effect of Cross Section Size of Steel Beam. The beam mechanism stage is the first stage of the progressive collapse 


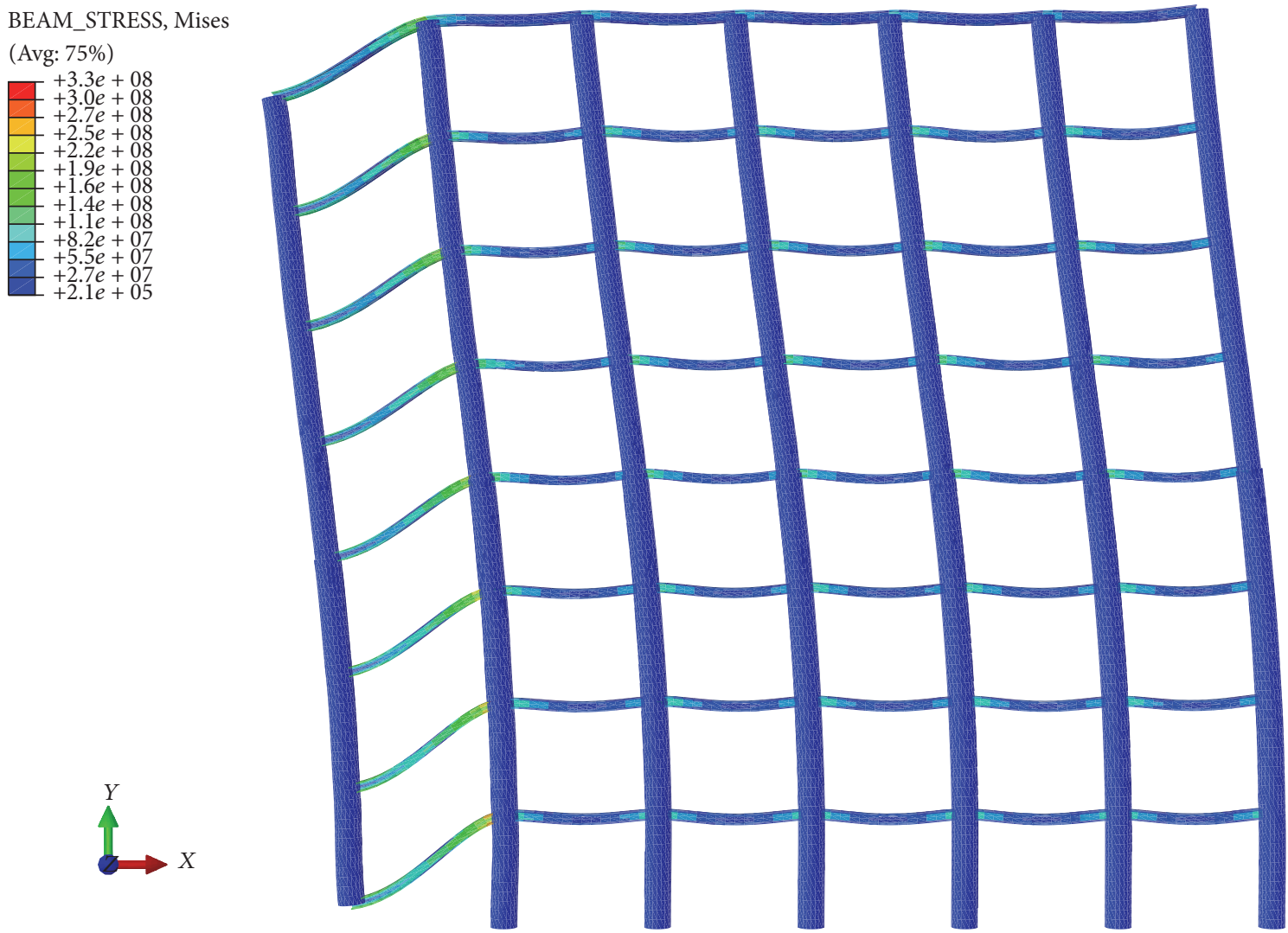

FIGURE 15: Deformation of the hybrid frame after the failure of the bottom corner column.

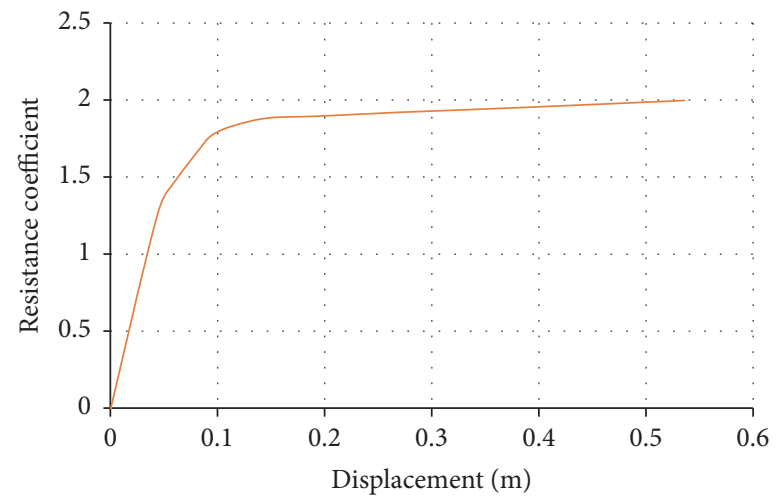

(a) Static displacement-resistance coefficient curve

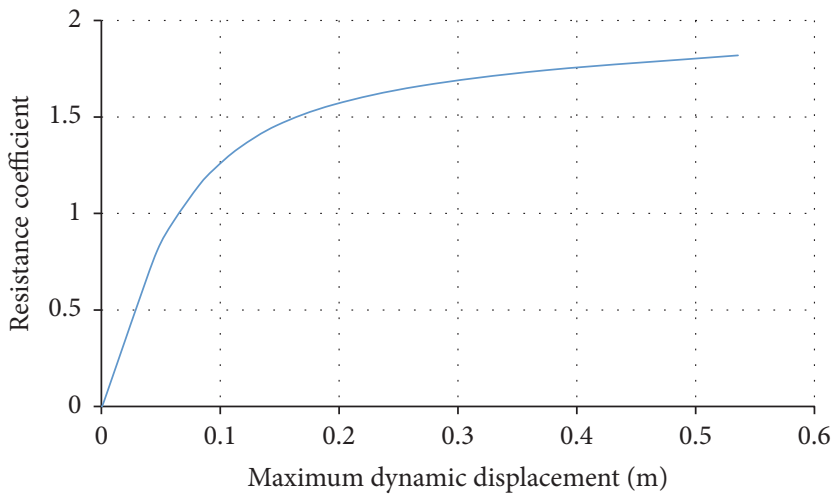

(b) Dynamic displacement-resistance coefficient curve

FIgURE 16: Vertical displacement-resistance coefficient curve of the hybrid structure after the failure of the bottom corner column.

process of the SRC column-steel beam hybrid frame. In that stage the anticollapse ability of the structure is mainly provided by the bearing capacity of the beam. Therefore the cross-sectional size of the beam has a direct effect on the progressive collapse of the structure. In addition, changing the beam cross-sectional dimensions, the beam-to-column linear stiffness ratio of the frame will also change. Also the beam-to-column linear stiffness ratio is an important factor in determining the integrity of the structure, which will affect the structure ductility, internal force distribution and energy consumption, and other properties. Therefore, this paper presents a parametric analysis for the hybrid frame with different beam cross-sectional dimensions and corresponding beam-to-column linear stiffness ratios, which is shown in Table 3.

4.2.1. Removing Bottom Middle Column. The curves of the vertical displacement versus resistance coefficient of the hybrid frame with different beam parameters (Table 3) after 


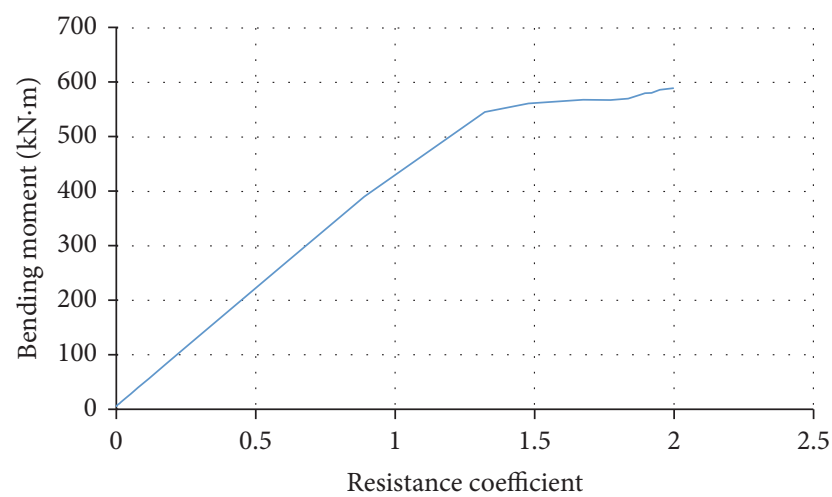

FIGURE 17: Bending moment-resistance coefficient curve of the steel beam connected with the removed corner column.

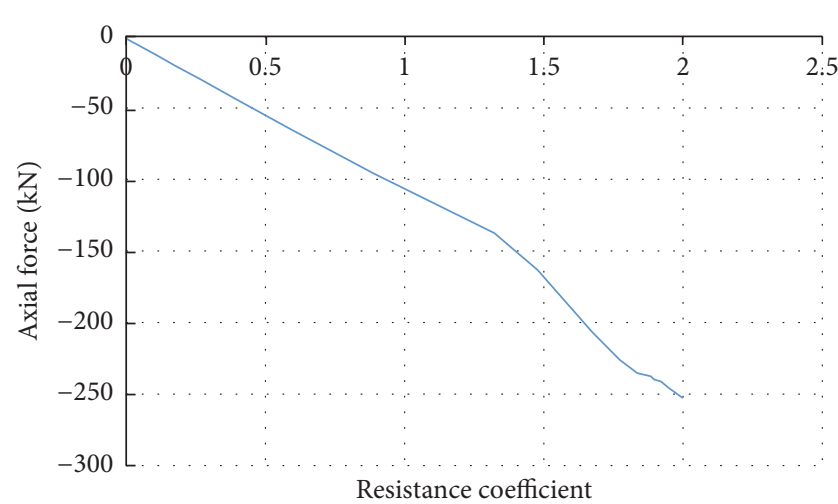

Figure 18: Axial force-resistance coefficient curve of the steel beam connected with the removed corner column.

TABLE 3: Beam dimension and corresponding beam-to-column linear stiffness ratios (models (4)-(7)).

\begin{tabular}{lccc}
\hline Model & $\begin{array}{c}\text { Beam dimension }(\mathrm{mm}) \\
(\text { height } \times \text { width } \times \text { web } \\
\times \text { flange })\end{array}$ & $\begin{array}{c}\text { Beam-to- } \\
\text { column linear } \\
\text { stiffness ratios } \\
\text { in storeys } 1-4 \\
\left(i_{b} / i_{c}\right)\end{array}$ & $\begin{array}{c}\text { Beam-to- } \\
\text { column linear } \\
\text { stiffness ratios } \\
\text { in storeys } 5-8 \\
\left(i_{b} / i_{c}\right)\end{array}$ \\
\hline$(4)$ & $350 * 250 * 12 * 16$ & 0.143 & 0.218 \\
$(5)$ & $400 * 250 * 14 * 16$ & 0.195 & 0.292 \\
$(6)$ & $400 * 250 * 16 * 24$ & 0.266 & 0.401 \\
$(7)$ & $450 * 250 * 16 * 24$ & 0.421 & 0.562 \\
\hline
\end{tabular}

removing the bottom middle column are presented in Figure 21.

It can be seen from Figure 21 that the trend of the four curves is consistent. When the structure reaches the failure criterion with the vertical displacement of $0.48 \mathrm{~m}$, the resistance coefficients of the four models are 2.07, 2.58, 2.97, and 3.76, respectively. It indicates that the steel cross section size is closely related to the final progressive collapse bearing capacity of the hybrid frame. The larger the cross section is, the stronger the ultimate resistance of progressive collapse will be. The reason is that the ultimate progressive collapse bearing capacity of the hybrid frame is greatly influenced by

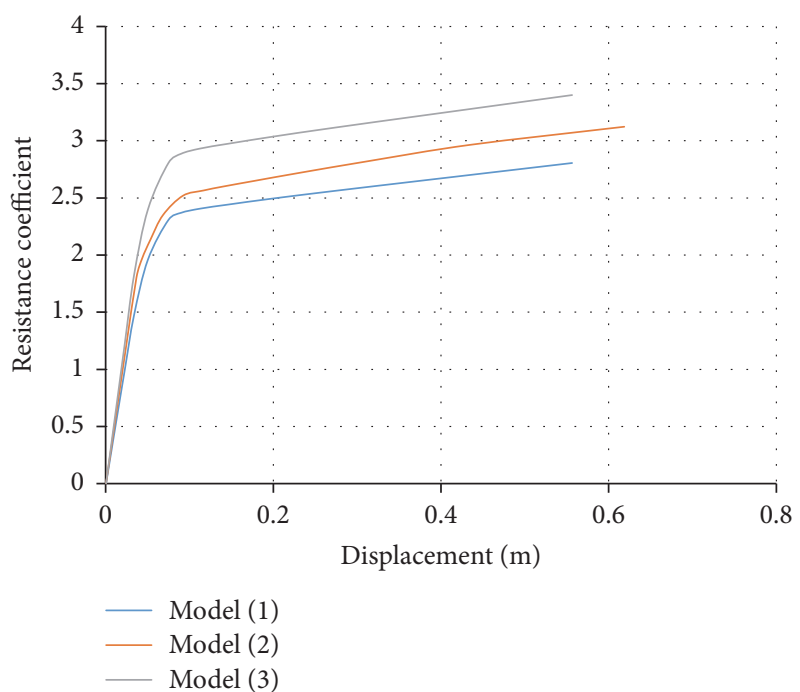

FIGURE 19: Displacement-resistance curve of the three models with different steel ratio after the bottom middle column was removed.

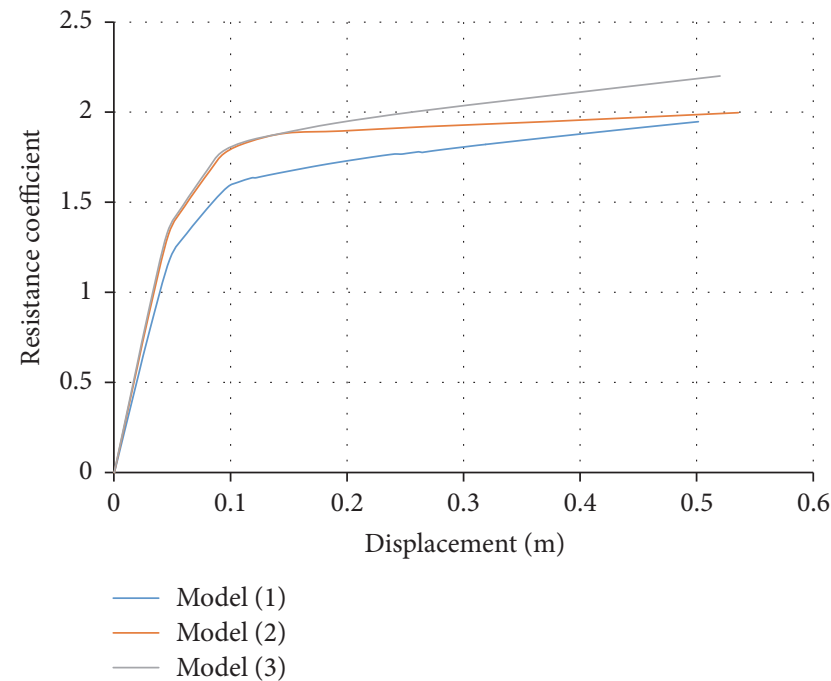

FIGURE 20: Displacement-resistance curve of the three models with different steel ratio after the bottom corner column was removed.

the ultimate moment of the "beam mechanism" stage, which is closely related to the beam section size.

4.2.2. Removing Bottom Corner Column. The curves of the vertical displacement versus resistance coefficient of the hybrid structure from the three models (Table 3 ) after removing the bottom corner column are given in Figure 22. It shows similar trend as Figure 21. With the increase of the cross-sectional dimension of the steel beam, the resistance coefficient of the model increases correspondingly, at values of $0.95,1.47,1.96$, and 2.63 when the frame reaches the failure criterion. Again it indicates that the progressive collapse behavior of the SRC column-steel beam hybrid frame has a very close relationship with the cross section of the beam. It is worth noting that when the section of steel beam is 


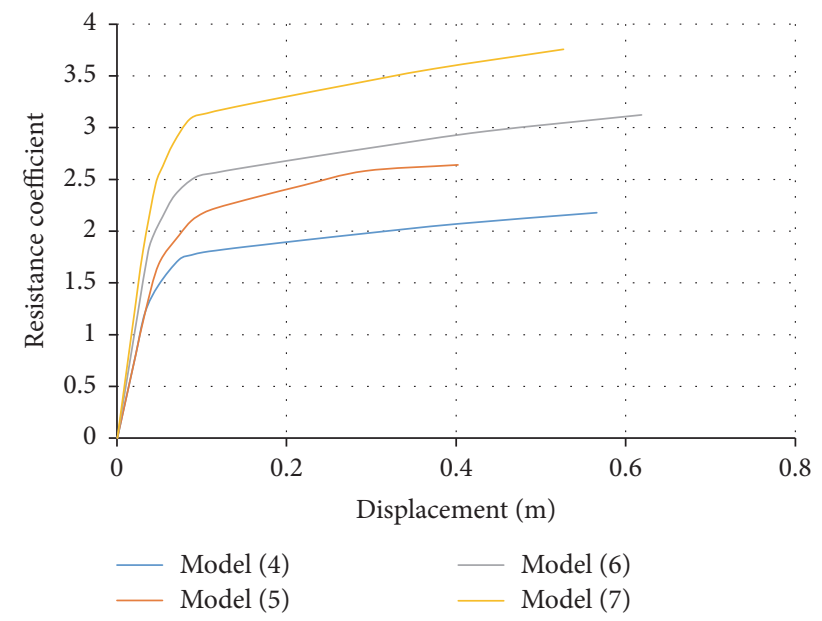

FIGURE 21: Vertical displacement-resistance coefficient relationship of models with different beam parameters after removing the bottom middle column.

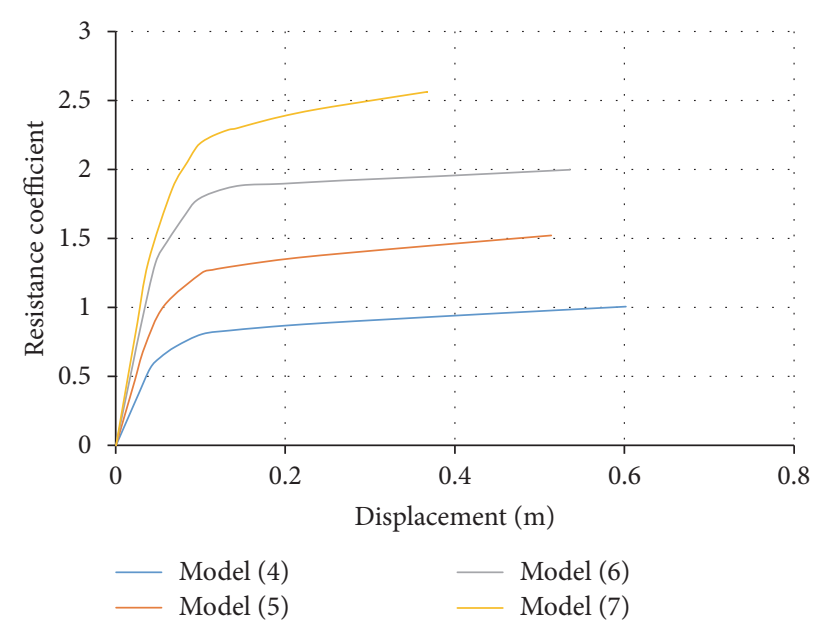

FIGURE 22: The vertical displacement-resistance coefficient relationship of models with different beam parameters after removing the bottom corner column.

$350 * 250 * 12 * 16$ (the stiffness ratio of beam and column is 0.143 ), the resistance coefficient is 0.95 . That is, after removing the vertical member, the progressive collapse of the hybrid frame will occur under normal load.

4.3. Effect of the Different Vertical Demolition Positions. The effects of the removal of the middle column and the corner column on the progressive collapse behavior and the corresponding collapse mechanism are studied in the previous section; however, both analyses are about removal of the bottom storey column elements. To investigate more the effect of the vertical position of the removal column on the progressive collapse behavior, further pushdown analysis was conducted on the first, fourth, and seventh storey columns to represent the lower, middle, and upper parts of the structure.

Figures 23 and 24 are the curves of the vertical displacement versus the resistance coefficient at the control node for removal of the middle column and the corner column in

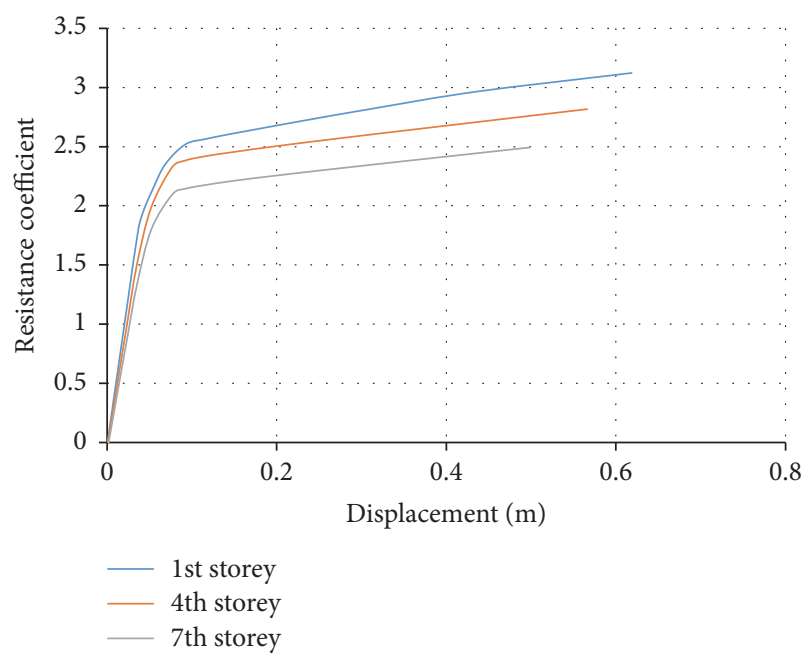

FIGURE 23: Vertical displacement-resistance coefficient curves obtained by removing the middle column in different floors.

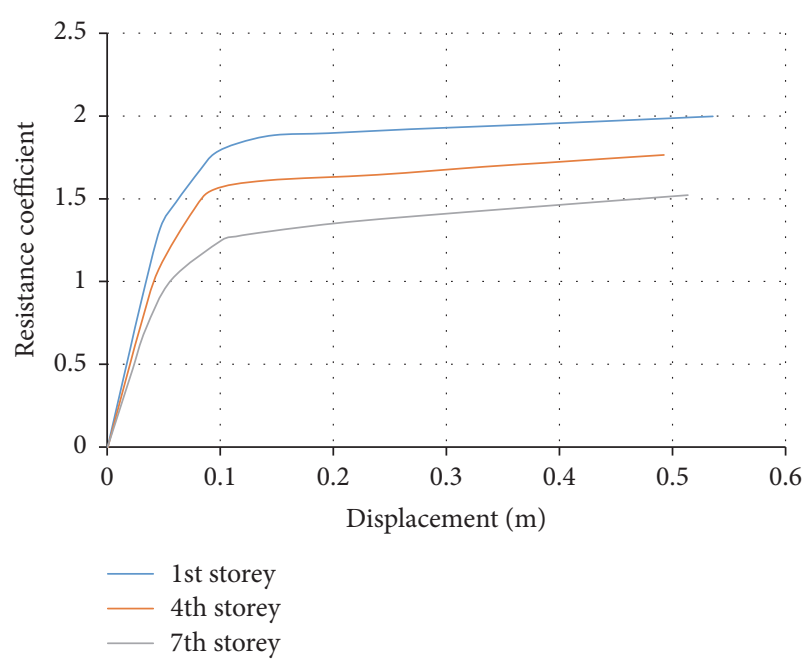

FIGURE 24: Vertical displacement-resistance coefficient curves obtained by removing the corner column in different storeys.

different floors. It can be seen from the curves that, for both middle column and corner column removal, the lower the vertical position of the removed column is, the greater the load resistance coefficient of the structure is at the limit of the failure criterion. It also indicates that the cross section of the column needs to be designed stronger if the lower columns are considered. In addition, the more the beam and column components which can form pull system are in the upper structure, the larger the redundancy is and the more the load transferring path that could be obtained is, and hence more elements can be inbolved in the process of internal force redistribution.

\section{Conclusion}

In this paper, the ABAQUS program is used to establish the SRC column-steel beam hybrid frame model, of which the 
progressive collapse behavior is studied by both dynamic analysis and the pseudostatic pushdown method. The results of both methods agree well with each other. Some conclusions can be drawn from this investigation.

(1) For the bottom middle column removal case, the SRC column-steel frame has good resistance to progressive collapse under dynamic instantaneous load (impact effect from sudden column collapse). At the beginning of the loading, the progressive collapse resistance of hybrid frame is provided by the bending capacity of the steel beam (beam mechanism). And after the beam reaches its ultimate moment, the frame collapse resistance is provided by the tensile capacity of steel beam (catenary mechanism).

(2) For the bottom corner column removal case, the SRC column-steel frame does not collapse under dynamic instantaneous load (impact effect from sudden column collapse). But its resistance to progressive collapse is relatively smaller than that of middle column being removed. In addition, when the steel beam reaches the ultimate moment, the residual structure cannot bear any more vertical load, and there is no catenary mechanism system formed after the beam mechanism system.

(3) Increasing the steel ratio in the SRC column can slightly improve the progressive collapse bearing capacity of the SRC column-steel beam hybrid structure.

(4) Because the ultimate progressive collapse bearing capacity of the hybrid frame is greatly influenced by the ultimate moment of the "beam mechanism" stage, increasing the cross section of the steel beam can significantly improve the progressive collapse behavior of the hybrid frame.

(5) The lower the position of the removed column in the structure, the better the progressive collapse behavior of hybrid structure system and the greater the load resistance coefficient of the structure.

\section{Conflicts of Interest}

The authors declare that there are no conflicts of interest regarding the publication of this paper.

\section{Acknowledgments}

The first author would like to express gratitude to the National Natural Science Foundation of China for the financial support (Grant no. 51408556).

\section{References}

[1] C. Pearson and N. Delatte, "Lessons from the progressive collapse of the Ronan Point apartment tower," in Proceedings of the 3rd Congress Forensic Engineering, pp. 191-200, October 2003.

[2] ASCE7-05, Minimum Design Loads for Buildings and Other Structures, American Society of Civil Engineers, Reston, Va, USA, 2005.

[3] DOD2010, Design of Structures to Resist Progressive Collapse, Department of Defense, Washington, DC, USA, 2010.

[4] Unitde States General Service Adminisration (GSA), Progressive Collapse Analysis and Design Guidelines for News Federal Office Buildings and Major Modernization Project, 2003.
[5] Structural Use of Concrete. Part 1: Code of Practice for Design and Construction, British Standard Institute, 1997.

[6] D. B. Moore, "The UK and European regulations for accidental actions," in Proceedings of the Workshop on Prevention of Progressive Collapse, National Institute of Building Sciences, Washington, DC, USA, 2002.

[7] Daft prEN1991-1-7, Eurocode 1: Actions on Structures. Part 1-7: General Actions-Accidental Actions, European Committee for Standardization, 2005.

[8] M.-H. Tsai and B.-H. Lin, "Investigation of progressive collapse resistance and inelastic response for an earthquake-resistant RC building subjected to column failure," Engineering Structures, vol. 30, no. 12, pp. 3619-3628, 2008.

[9] J. Kim and T. Kim, "Assessment of progressive collapse-resisting capacity of steel moment frames," Journal of Constructional Steel Research, vol. 65, no. 1, pp. 169-179, 2009.

[10] M. Liu, "A new dynamic increase factor for nonlinear static alternate path analysis of building frames against progressive collapse," Engineering Structures, vol. 48, pp. 666-673, 2013.

[11] E. Masoero, P. Darò, and B. M. Chiaia, "Progressive collapse of 2D framed structures: an analytical model," Engineering Structures, vol. 54, pp. 94-102, 2013.

[12] Y. Liang, X. Lu, and Y. Li, "Design method to resist progressive collapse for a three story RC frame," Journal of PLA University of Science and Technology, vol. 8, no. 6, pp. 659-664, 2007 (Chinese).

[13] W. Yi, Q. He, and Y. Xiao, "Collapse performance of RC frame structure," Journal of Building Structures, vol. 28, no. 5, pp. 104117, 2007 (Chinese).

[14] Y. Li, X. Lu, L. Ye, and S. Chen, "Study on progressive-collapse resistance capacity of RC frame structures based on Pushdown analysis," Journal of Shenyang Jianzhu University (Natural Science), vol. 27, no. 1, pp. 10-18, 2011 (Chinese).

[15] A. Fascetti, S. K. Kunnath, and N. Nisticò, "Robustness evaluation of RC frame buildings to progressive collapse," Engineering Structures, vol. 86, pp. 242-249, 2015.

[16] GB 50010-2010, Code for Design of Concrete Structure, China Construction Industry Press, Beijing, China, 2010 (Chinese).

[17] F. Li and G. Zhao, "Study on seismic behavior of composite frame with SRC columns and steel beam," Industrial Construction, vol. 40, no. 9, pp. 111-114, 2010 (Chinese).

[18] K. Khandelwal and S. El-Tawil, "Pushdown resistance as a measure of robustness in progressive collapse analysis," Engineering Structures, vol. 33, no. 9, pp. 2653-2661, 2011.

[19] CECS392-2014, Code for Design of Collapse Resistance of Building Structures, China Planning Press, Beijing, China, 2014 (Chinese).

[20] JGJ138-2001, “Technical specification for steel reinforced concrete composite structures," Tech. Rep., China Architecture Industry Press, Beijing, China, 2002 (Chinese). 


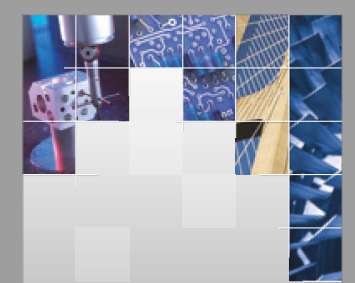

\section{Enfincering}
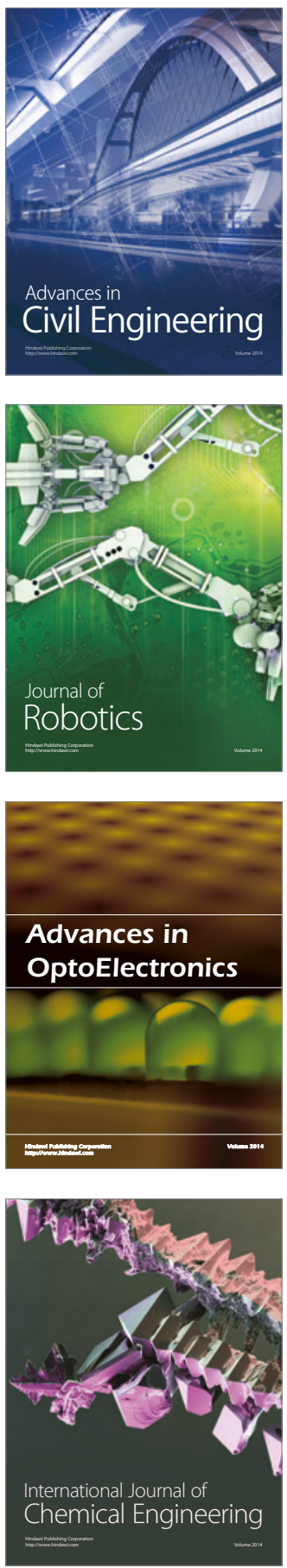

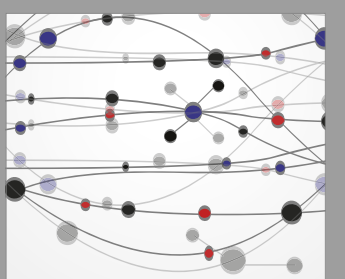

The Scientific World Journal

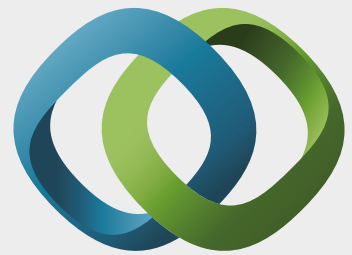

\section{Hindawi}

Submit your manuscripts at

https://www.hindawi.com
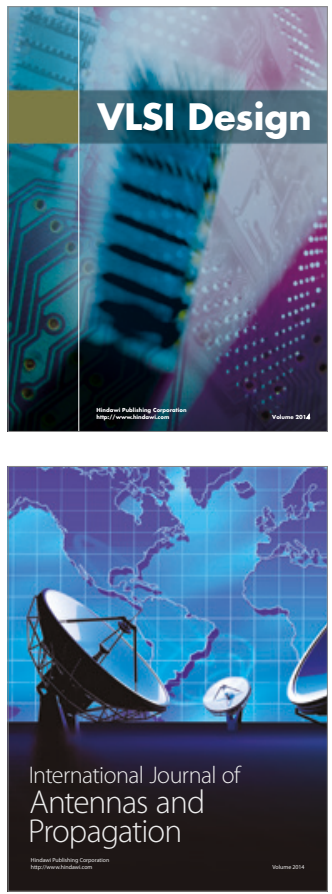

\section{Rotating}

Machinery
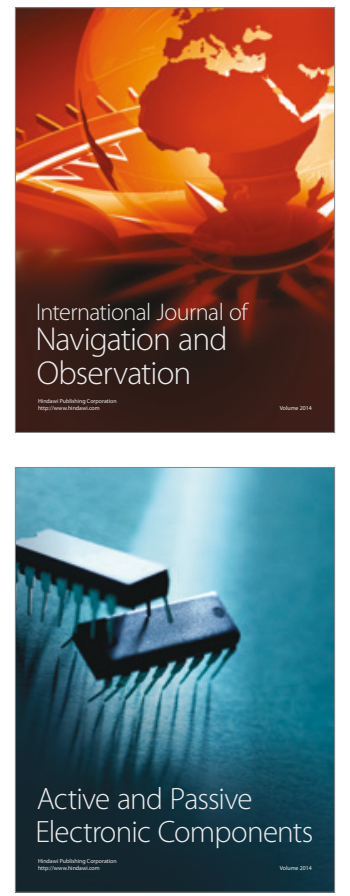
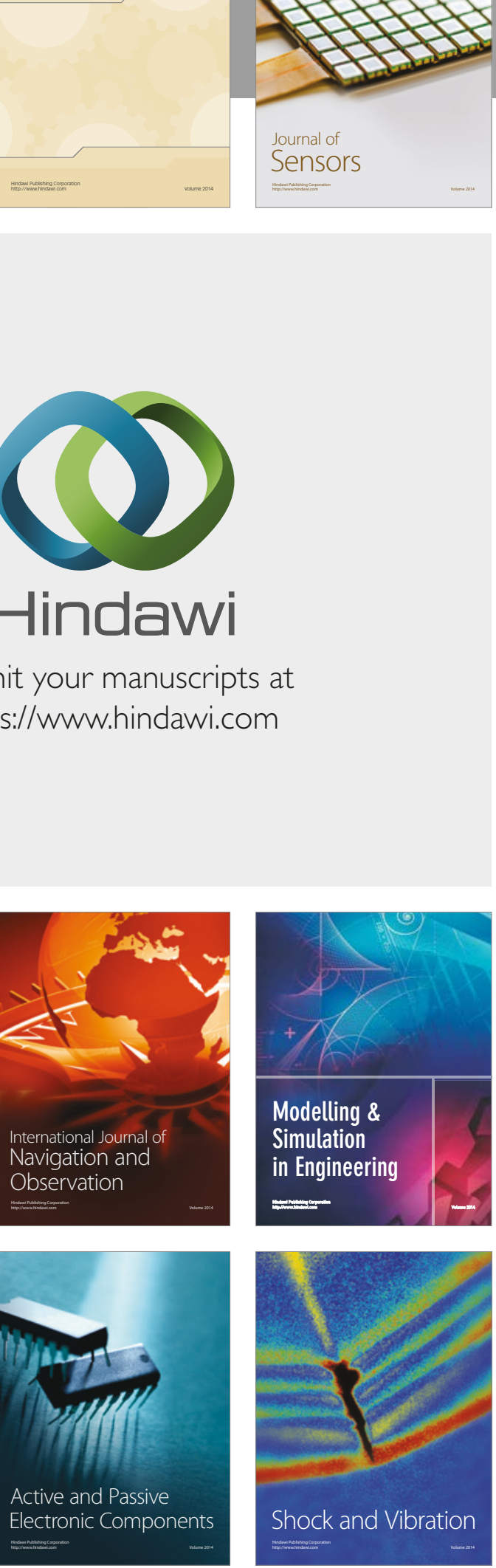
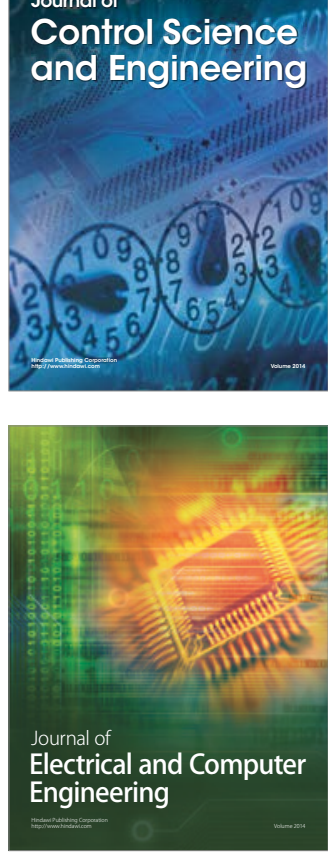

Distributed

Journal of

Control Science

and Engineering
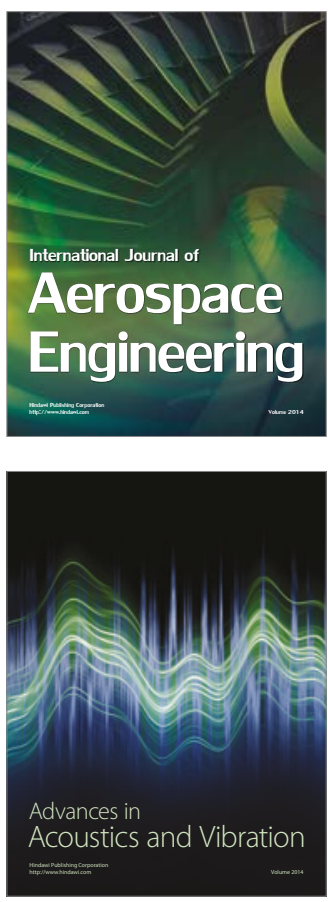

Sensor Networks 